\section{A RESPONSE TO GOSPORT: REGIONAL PROJECT ON ANTICIPATORY PRESCRIBING AND BENCHMARKING PRACTICE CROSS-HOSPICE IN YORKSHIRE}

Laura Deacon, Alice Pullinger, Sarah Callin, Hazel Pearse, Liz Brown. St Catherine's Hospice, Scarborough, Prince of Wales Hospice, Pontefract, St Michael's Hospice, Harrogate

\subsection{6/spcare-2020-PCC.75}

Background and introduction The findings of the enquiry into events at the Gosport Hospital, published in June 2018, demonstrated shocking misuse of opioid and benzodiazepine medications and syringe drivers leading to the shortening of many lives. Hospices frequently utilise opioid and benzodiazepine medications, including via syringe driver, and need to be able to demonstrate that their practice is safe and appropriate.

Methods Individual hospice units developed their own responses to the Gosport report. Both Prince of Wales and St Catherine's Hospice undertook retrospective audits of hospice inpatient unit care. St Catherine's Hospice presented their work for discussion at the regional 'Learning group' meeting.

Results The two sites utilised different collection proforma and reviewed care given to 93 hospice inpatient unit patients, demonstrating safe and appropriate practice at both hospices. Anticipatory prescribing was personalised to the patient, considering factors such as renal function, and was judged 'appropriate' in $82-100 \%$ of cases. 80 patients died and, as anticipated, there was significant use of opioids, benzodiazepines and syringe drivers. The use of opioids and syringe drivers was found to be proportionate and appropriate. Areas for improvement included recording of indication for both prescription and administration of medications. Through discussion of these results, it was acknowledged that a regional approach to auditing to allow 'benchmarking' between Hospice units would be advantageous in standard setting and comparison. Both pilot proformas had strengths and weaknesses and are being utilised to develop a regional audit proforma with plans to establish regular audit and re-audit cycles. Conclusions As specialists with a high use of opioid and benzodiazepine medications, there is a need to demonstrate that our use of these medications is safe, consistent and of exemplary standard. The hope is that this approach will allow identification of any areas of difference in practice and offer quality assurance across region and Hospice.

\section{PLACING DEATH AND DYING: ON THE WORK OF MAKING PLACE AT THE END OF LIFE}

Annelieke Driessen, Erica Borgstrom, Simon Cohn. London School of Hygiene and Tropical Medicine; The Open University

\subsection{6/spcare-2020-PCC.76}

Background Palliative care policy and professionals are concerned about the location of care, epitomised in phrases like 'preferred place of care' and 'preferred place of death'. There has been an emphasis on home being the ideal place. Conversely, it is recognised that high quality palliative and end-oflife care can be delivered in a wide variety of settings.

Methods This presentation is part of the ongoing Forms of Care project about palliative care. Ethnographic methods include observation of over 60 in- and outpatient palliative care team meetings, 1 year of shadowing palliative care team members in their daily work, and 15 interviews with palliative care staff, including doctors, nurses, social workers, and physiotherapists. Three patients and their families were also interviewed multiple times. Data was thematically analysed, drawing on social theory.

Results Palliative care professionals consider place as part of the care they deliver. Hospital was typified as a place of control, known infrastructure, skilled staff and support, and constant monitoring. The home was a place of being a 'guest' and unknown quantity, creating a shift in power dynamics between professionals, and patients and their families. The drive for patients to be cared for at home came with added costs in terms of resources and the emotional labour. However, many cases extended beyond this binary. We highlight the work both professionals and patients do to keep a place stable. We suggest such efforts of 'placing' show how place is not merely a geographical location, but made through relations, interactions and activities.

Conclusion In the push to enable patients to die at home, what tends to be overlooked is the work that goes into 'placing': the work of 'making place'. The research indicates the importance of understanding how placing gets done as a form of care.

\section{ADVANCED CARE PLANNING IN PATIENTS ADMITTED FROM CARE HOMES TO THE EMERGENCY DEPARTMENT}

Rachel M Fardon, Emily Moore, Laura M Nightingale. Kingston Hospital

\subsection{6/spcare-2020-PCC.77}

Background Early identification of patients in their last year of life is a national focus, enabling the expression of preferences through Advance Care Planning (ACP). This is particularly relevant to patients in nursing homes, who die on average within 18 months of admission. This service evaluation aimed to establish if ACPs are followed appropriately by care homes and hospital staff.

Methods Retrospective data collection was undertaken for patients aged $>75$ admitted to the Emergency Department over a 6-week period (January-February 2019). A total of 120 patients from care homes were included. Review of the Coordinate My Care (CMC) database identified which patients had existing ACPs.

Results $17 \%$ of patients had a CMC record on admission. $26 \%$ had one created subsequently, and $57 \%$ had no CMC record. The most common recorded diagnoses were Dementia (45\%) and Frailty (25\%). 30\% of patients were 'For treatment of reversible conditions in the home/hospice setting'. Hospital admissions for these patients should theoretically be avoided, but in $83 \%$ of cases there was no acknowledgement of their $\mathrm{CMC}$ record. For patients who had a CMC record created during or post admission, 61\% were identified as not for readmission. This group had the highest proportion of subsequent deaths (26\%) and lowest number of subsequent admissions (0.4 per patient).

Conclusion Less than 20\% of patients from care homes had a pre-existing CMC record, despite being a group to target for ACP. $30 \%$ of admissions were inappropriate and $16 \%$ of patients with newly created CMC records had subsequent inappropriate admissions (including two inpatient deaths). Further work is required to identify the challenges to managing patients within the community and factors contributing to hospital admission. Finally, when patients had a pre-existing $\mathrm{CMC}$ record there was poor recognition of this. Improved 